\title{
Pemanfaatan Wireless Dalam Perancangan Prototype Siram Bawang Merah Berbasis Arduino
}

\author{
Eko Budiraharjo \\ Email: ekobudiraharjo@upstegal.ac.id \\ Program Studi Informatika, Fakultas Teknik dan Ilmu Komputer, Universitas Pancasakti Tegal
}

\begin{abstract}
Abstrak
Dalam perancangan alat siram bawang merah berbasis Arduino menggunakan perangkat keras diantaranya yaitu wireless, wemos d1 mini, step down, terminal tembaga, kabel male female, relay 4 module, tombol switch, gearbox dinamo 12 volt dan aki 12 volt. Dalam pemrograman sistem alat siram ini menggunakan software Arduino IDE untuk menghubungkan wemos d1 mini dengan aplikasi Blynk di smartphone melalui jaringan wifi, dimana aplikasi Blynk digunakan sebagai pengontrol jalannya alat siram. Atribut yang digunakan dalam perancangan alat siram menggunakan metode EFD (Ergonomic Function Deployment) yaitu dengan kebutuhan responden akan penggunaan alat siram yaitu (1) alat siram dapat menyiram bawang merah (2) pengoperasian alat siram mudah digenggam (3) beban pengoperasian alat siram ringan (4) alat siram tidak panas saat digunakan (5) tidak menimbulkan cedera (6) mempercepat waktu kerja. Dari hasil perhitungan konsumsi energi yang dilakukan terhadap pesaing 1 diketahui bahwa tingkat pekerjaannya adalah berat dikarenakan nilai konsumsi energi berada diantara 1,5 - 2,0 kkal/menit sedangkan pesaing 2 tingkat pekerjaanya adalah ringan dikarenakan nilai konsumsi energi berada diantara $0,5-1,0 \mathrm{kkal} / \mathrm{menit}$ sehingga berdasarkan data tersebut pesaing 2 atau alat siram bawang merah berbasis IOT dapat mengurangi beban kerja petani bawang saat melakukan proses penyiraman bawang merah.
\end{abstract}

Kata kunci : Wireless, Arduino Uno, Wemos, Sensor, LCD

\section{Pendahuluan}

Desa Sigentong adalah salah satu desa penghasil bawang merah terbesar di Kecamatan Wanasari, Kabupaten Brebes. Dalam budidaya tanaman bawang merah ini, masalah yang dapat mengurangi produksi atau hasil panen yaitu perawatan tanaman bawang merah yang agak sulit. Tanaman bawang merah memiliki sistem perakaran yang dangkal dan sangat rentan terhadap hilangnya kelembaban dari lapisan atas tanah sehingga irigasi atau pengairan tambahan yang efisien harus disediakan untuk mempertahankan pertumbuhan [16]. Oleh sebab itu, maka diperlukan sebuah alat siram tanaman bawang yang efektif dan ergonomis untuk menjaga pertumbuhan tanaman bawang, karena proses penyiraman ini merupakan aspek penting dalam proses budidaya tanaman bawang.

Hasil dari observasi dan wawancara yang dilakukan terhadap pekerja penyiram bawang merah di Desa Sigentong diketahui bahwa pekerja masih menggunakan alat manual dalam proses penyiraman tanaman bawang merah sehingga menyebabkan beberapa keluhan pada tubuh pekerja. Sebagian besar pekerja penyiram bawang merah sudah bekerja selama lebih dari 15 tahun. Semua pekerja berjenis kelamin laki-laki dengan rentang usia $35-50$ tahun.
Penelitian awal ini dilakukan dengan melakukan penyebaran kuesioner Nordic Body Map (NBM) kepada 10 sampel pekerja penyiram bawang merah di Desa Sigentong untuk memperoleh informasi keluhan apa saja yang dirasakan oleh pekerja penyiram bawang merah selama melakukan pekerjaanya. Diperoleh data bahwa keluhan rasa sakit, pegal-pegal dan nyeri terbanyak pada bagian tubuh leher, punggung, pinggang, bahu, lengan, pergelangan tangan dan tangan. Keluhan tersebut yaitu sebanyak $80 \%$ sakit pinggang, $70 \%$ sakit pergelangan tangan kanan, 60\% sakit tangan kanan, leher bagian bawah dan lengan atas kanan, 50\% sakit leher bagian atas, bahu kanan, punggung, lengan bawah kiri dan lengan bawah kanan. Dari data tersebut mengindikasikan bahwa pekerja mengalami kelelahan otot, hal ini dikarenakan alat penyiram bawang yang digunakan saat ini kurang ergonomis disebabkan masih menggunakan alat penyiraman secara manual, sehingga menyebabkan beban kerja yang berat pada pekerja penyiram bawang.

Berdasarkan permasalahan tersebut, penulis ingin merancang alat siram tanaman bawang berbasis IOT (Internet Of Things), yaitu merupakan sebuah konsep yang bertujuan untuk memperluas manfaat dari konektivitas internet yang tersambung secara terusmenerus yang memungkinkan kita untuk 
menghubungkan mesin, peralatan, dan benda fisik lainnya dengan sensor jaringan dan aktuator untuk memperoleh data dan mengelola kinerjanya sendiri, sehingga memungkinkan mesin untuk berkolaborasi dan bahkan bertindak berdasarkan informasi baru yang diperoleh secara independen [6]. Kemudian dikendalikan dengan smartphone menggunakan metode rancangan Ergonomic Function Deployment (EFD), adalah metode untuk memudahkan selama proses perancangan, pembuatan keputusan "direkam" dalam bentuk matrik-matrik sehingga dapat diperiksa ulang serta dimodifikasi di masa yang akan datang. Biasanya untuk mengetahui ergonomis atau tidaknya hasil rancangan [17]. Dengan aspek ergonomis yang dipakai dalam merancang, alat ini diharapkan bisa mengurangi beban kerja petani bawang saat melakukan proses penyiraman bawang.

\section{Metode Penelitian}

Dalam proses suatu penelitian tidak terlepas dari adanya metode penelitian yang akan digunakan selama proses penelitian tersebut. Metode penelitian merupakan cara utama yang digunakan peneliti untuk mencapai tujuan dan menentukan jawaban atas masalah yang diajukan. Pada penelitian ini penulis menggunakan metode eksperimen. Metode eksperimen dapat diartikan sebagai pendekatan penelitian kuantitatif yang yang paling penuh, dalam arti memenuhi semua persyaratan untuk menguji hubungan sebab akibat.

Pada penelitian ini penulis menggunakan teknik pengumpulan data primer dan data sekunder. Data primer berasal dari hasil pengamatan secara langsung atau observasi, wawancara dan penyebaran kuesioner kepada subjek penelitian. Sedangkan data sekunder berasal dari studi literatur dan jurnal artikel referensi yang berkaitan dengan permasalahan penelitian.

Metode pengumpulan data merupakan cara untuk memperoleh suatu informasi yang dibutuhkan dalam proses pengolahan dan analisis data dalam penelitian. Pengumpulan data pada penelitian ini menggunakan metode pengumpulan data sebagai berikut:

\section{A. Observasi}

Metode observasi adalah mengamati secara langsung di lokasi penelitian dalam rangka mengumpulkan data yang berkaitan dengan masalah penelitian. Sambil melakukan pengamatan, peneliti ikut melakukan apa yang dikerjakan sumber data dan ikut merasakan beban kerja yang dirasakan. Dengan ikut serta melakukan pekerjaan yang dilakukan sumber data atau subjek penelitian maka data yang diperoleh akan lengkap, tajam, dan sampai mengetahui pada tingkat makna dari setiap perilaku yang nampak.

\section{B. Metode Eksperimen}

Metode eksperimen adalah mengadakan kegiatan percobaan untuk melihat suatu hasil variabel-variabel yang di selidiki, guna menemukan suatu kebenaran dan kemudahan dalam melakukan suatu kegiatan. Melakukan pengujian terhadap kendali alat yang sudah dirancang dan mengukur tingkat beban kerja petani bawang merah.

\section{Studi Pustaka}

Studi pustaka adalah metode yang dilakukan dengan membaca dan mempelajari dari sumber referensi atau literatur yang terkait dengan penelitian yang dilakukan, baik dari buku-buku, jurnal artikel, maupun sumber informasi lainya yang terpercaya yang digunakan sebagai bahan acuan dalam penelitian.

\section{Wawancara}

Wawancara adalah metode pengumpulan data melalui tanya jawab secara langsung kepada narasumber, untuk mendapatkan informasi secara menyeluruh mengenai permasalahan yang terjadi. Wawancara dilakukan juga untuk mengetahui kebutuhan yang diinginkan pengguna terhadap perancangan alat yang akan dibuat.

\section{E. Kuisoner}

Kuesioner metode pengumpulan data dengan cara memberi sebuah pertanyaan atau pernyataan tertulis kepada responden untuk di jawabnya. Kuesioner ini dibagikan kepada pekerja petani bawang merah di area persawahan bawang merah Desa Sigentong, Kecamatan Wanasari, Kabupaten Brebes.

\section{Hasil dan Pembahasan}

\section{A. Jaringan Wireless Nirkabel}

Jaringan wireless nirkabel adalah jaringan komputer yang menggunakan transmisi data nirkabel untuk menghubungkan antar node dalam suatu jaringan. Jaringan nirkabel menggunakan standar Institute of Electrical and Electronics Engineers 802.11 atau IEEE 802.11[2] IEEE merupakan 
organisasi yang mengatur standar mengenai teknologi nirkabel. Frekuensi kerja jaringan nirkabel adalah $2,4 \mathrm{GHz}, 3,7 \mathrm{GHz}$ dan $5 \mathrm{GHz}$. Jaringan nirkabel dapat diklasifikasikan menjadi 2 kategori yaitu jaringan nirkabel dengan infrastruktur dan jaringan nirkabel tanpa infrastruktur Jaringan ad-hoc adalah jaringan nirkabel multi hop yang terdiri dari banyak mobile node yang bersifat spontan dan dinamis. Jaringan ad-hoc memiliki keunggulan dibandingkan jaringan lain seperti tidak memerlukan dukungan backbone infrastruktur atau sarana pendukung transmisi data, node yang dapat bergerak bebas saat mengakses informasi secara real time ketika berhubungan, fleksibel terhadap suatu keperluan, dan dapat dikonfigurasi dalam beragam topologi. Taksonomi protokol routing di jaringan komputer. Mobile Ad-Hoc Network MANET merupakan jenis jaringan ad-hoc yang dapat berubah lokasinya dan melakukan konfigurasi sendiri dengan cepat. Pada jaringan MANET, mobile node bergerak kemanapun dengan kecepatan tertentu dan mengirimkan paket data secara peer-to-peer. Mobile node pada jaringan MANET dapat berperan sebagai pengirim, penerima data atau perantara untuk mobile node lainnya. MANET dapat dibentuk dimana saja dan kapan saja selama 2 node atau lebih.

\section{B. Perencanaan Desain}

Pembuatan pemrograman dari alat ini yaitu menggunakan software Arduino IDE, yaitu suatu source code yang mencakup beberapa program untuk menjalankan arduino, dimana penelitian ini boar arduino yang digunakan yaitu wemos d1 mini yang dapat menghubungan program melalui jaringan wifi yang kemudian terhubung ke aplikasi blynk yang digunakan sebagai pengontrol alat siram yang akan diteliti. Tampilan Arduino IDE terlihat seperti pada gambar 1 .

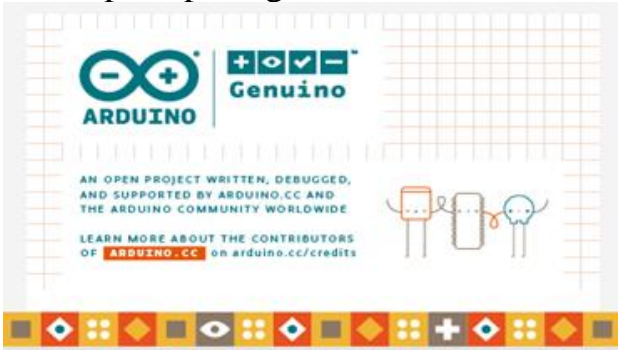

Gambar 1. Login Arduino IDE

Setelah itu dilakukan pemrograman untuk menghubungkan wemos d1 mini dengan aplikasi blynk seperti pada gambar dibawah ini.

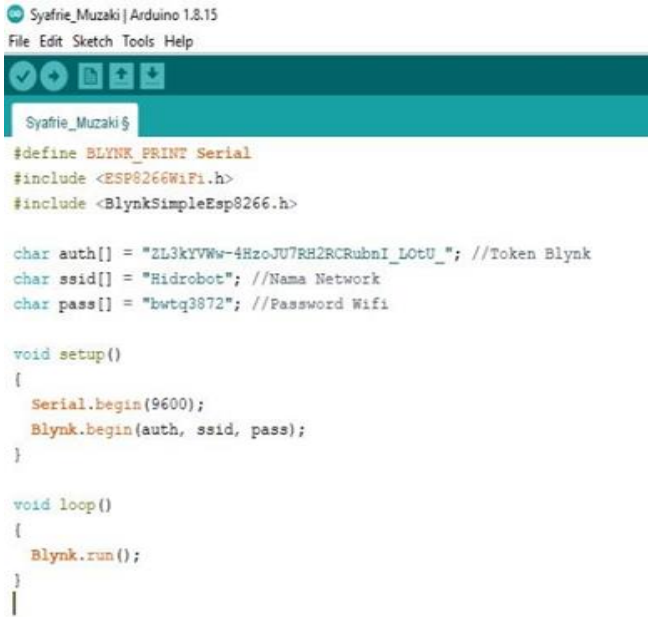

Gambar 2. Tampilan Pemrograman

Source code \#include <ESP8266wifi.h> dan \#include <BlynkSimpleEsp8266.h> merupakan program untuk memanggil library yang sudah ditambahkan pada tahap sebelumnya, yang digunakan untuk memudahkan pada saat proses pembuatan program. Source code \#include <ESP8266wifi.h> merupakan library yang digunakan untuk mengkoneksikan alat dengan jaringan wifi dan source code <BlynkSimpleEsp8266.h> merupakan library yang digunakan untuk mengkoneksikan alat dengan aplikasi blynk yang digunakan sebagai pengontrol alat.

Setelah itu dilakukan pengisian auth token blynk yang diperoleh setelah melakukan pembuatan project pada aplikasi blynk dengan seri token seperti terlihat pada gambar 4.2 dan dilanjutkan dengan mengganti nama wifi "Hidrobot" dan password wifi "bwt 3872" yang akan digunakan untuk mengkoneksikan alat.

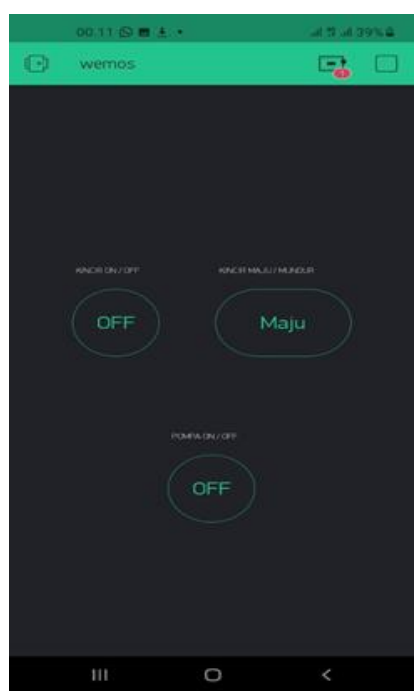

Gambar 3. Tampilan Tombol Operasi Pada Aplikasi Blynk 


\section{Rancangan Perangkat Keras Alat}

Proses ini merupakan tahap penggabungan dari beberapa perangkat keras yang digunakan. Perakitan yang dilakukan yaitu diawali dengan membuat jaringan kabel positif dan negatif pada terminal tembaga yang kemudian akan disalurkan ke perangkat relay 4 module, 2 step down, wemos $\mathrm{d} 1 \mathrm{mini}$, volt meter, dinamo gearbox dan pompa air. Pada relay 4 module dilakukan penjumperan kabel yang dilakukan untuk mengatur aliran listrik untuk menjalankan dan mematikan operasi dari alat tersebut. 2 step down yang digunakan untuk menurunkan tegangan arus dari daya atau aki yang mengalir ke wemos d1 mini dan relay 4 module, dimana daya atau aki bertegangan $12 \mathrm{v}$ sedangkan wemos $\mathrm{d} 1$ mini dan relay 4 module bertegangan $5 \mathrm{v}$. Dan yang terakhir yaitu pemasangan tombol switch on/off agar alat ini juga bisa dijalankan tanpa menggunakan internet seperti terlihat pada gambar dibawah ini.

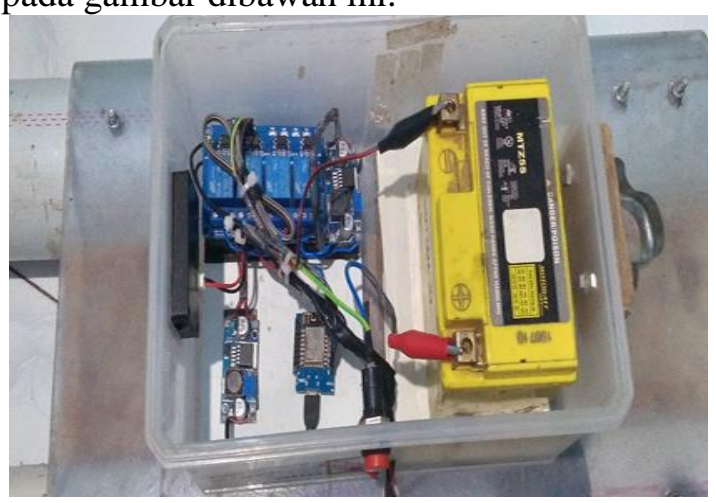

Gambar 4. Rancangan Perangkat Keras

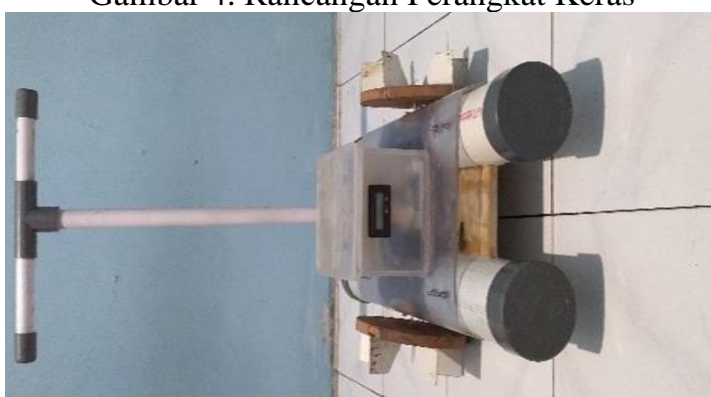

Gambar 5. Hasil Rancangan Alat Siram Bawang Merah

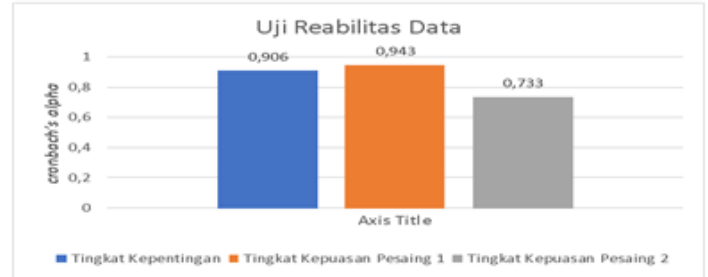

Gambar 6. Grafik Uji Reliabilitas Data

Uji Validitas Data :

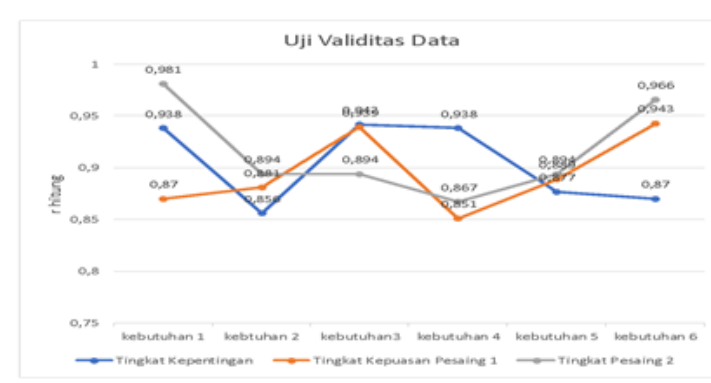

Gambar 7. Grafik Uji Validitas Data

Berikut ini merupakan hubungan kebutuhan responden terhadap karakteristik teknik sebagai berikut:

Tabel 1. Matriks Hubungan Kebutuhan Responden terhadap Kebutuhan Teknis

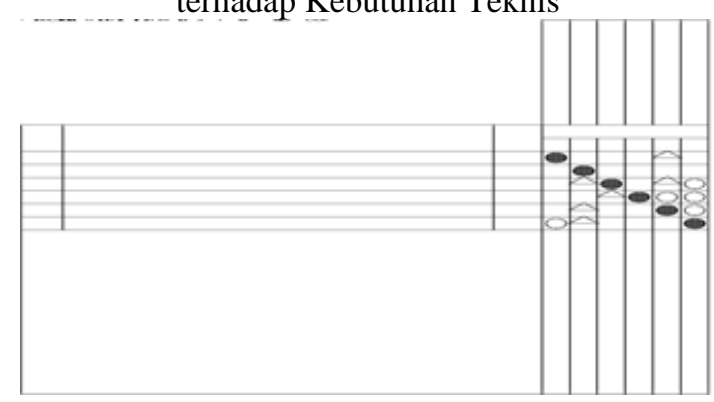

\section{Kesimpulan}

Dalam perancangan alat siram bawang merah berbasis IOT (Internet Of Things) menggunakan perangkat keras diantaranya yaitu wemos d1 mini, step down, terminal tembaga, kabel male female, relay 4 module, tombol switch, gearbox dinamo 12 volt dan aki 12 volt. Dalam pemrograman sistem alat siram ini menggunakan software Arduino IDE untuk menghubungkan wemos d1 mini dengan aplikasi Blynk di smartphone melalui jaringan wifi, dimana aplikasi Blynk digunakan sebagai pengontrol jalannya alat siram.

Atribut yang digunakan dalam perancangan alat siram menggunakan metode EFD (Ergonomic Function Deployment) yaitu dengan kebutuhan responden akan penggunaan alat siram yaitu (1) alat siram dapat menyiram bawang merah (2) pengoperasian alat siram mudah digenggam (3) beban pengoperasian alat siram ringan (4) alat siram tidak panas saat digunakan (5) tidak menimbulkan cedera (6) mempercepat waktu kerja

Dari hasil perhitungan konsumsi energi yang dilakukan terhadap pesaing 1 diketahui bahwa tingkat pekerjaannya adalah berat dikarenakan nilai konsumsi energi berada diantara $1,5-2,0 \mathrm{kkal} / \mathrm{menit}$ sedangkan 
pesaing 2 tingkat pekerjaanya adalah ringan dikarenakan nilai konsumsi energi berada diantara $0,5-1,0 \quad \mathrm{kkal} / \mathrm{menit}$ sehingga berdasarkan data tersebut pesaing 2 atau alat siram bawang merah berbasis IOT dapat mengurangi beban kerja petani bawang saat melakukan proses penyiraman bawang merah.

Saran bagi petani penyiram untuk memperhatikan lagi cara kerja penyiraman bawang agar dalam proses kerja tidak mengalami kelelahan atau beban kerja yang berat dikarenakan konsumsi energi dengan aktivitas kerja yang tidak seimbang sehingga dapat menyebabkan resiko kerja.

\section{Daftar Pustaka}

[1] Reza, A. Desrianty, F. H. M. Usulan Rancangan Tas Sepeda Trial Menggunakan Metode Ergonomic Function Deployment (EFD). Jurnal Online Institut Teknologi Nasional, 02(02), 353-363. Retrieved from https://ejurnal.itenas.ac.id/index.php/reka integra/article/view/531/738, 2014.

[2] Arafat S.Kom, M. K. Sistem Pengaman Pintu Rumah Bersasis Internet of Things (IoT) Dengan ESP8266. Technologia, 7(4), 263-265, 2016.

[3] Asnaldi, A. Pengenalan Macam-macam Udara \& Cara Mengukur Denyut Nadi. Retrieved from tp://wartawarga.gunadarma.ac.id/ 2010/01/, 2009.

[4] Bakar, I. A. Kenapa Perlu Penyiraman Tanaman. Retrieved from http://alamtanimoden.blogspot.com/2013 /12/penyiraman-tanaman.html, 2013.

[5] Diana Magrib, N. I. Pengukuran Beban Kerja Dengan Metode Fisiologi (Studi Kasus Pada "X" Fitness Center Ambon). MATRIK (Jurnal Manajemen Dan Teknik), $11(1), \quad 50$. https://doi.org/10.30587/matrik.v11i1.39 0, 2018.

[6] Efendi, Y. Internet of Things (IoT) Sistem Pengendalian Lampu Menggunakan Raspberry PI Berbasis
Mpbile. Jurnal Ilmiah Komputer, 4(1), 32-33, 2018.

[7] Eppinger, K. T. U. and S. D. Product Design and Development (5th ed.). New York: McGraw Hill Education, 2011.

[8] Ginting, R. Perancangan Produk. Yogyakarta: Graha Ilmu, 2010.

[9] Grandjean, E. Fitting the Task to The Man: A Textbook of Occupational Ergonomics Taylor and Francis (4th ed.). London, 1998.

[10] Handayani, R. Metodologi Penelitian Sosial. Yogyakarta: Trussmedia Grafika, 2020.

[11] Kadir, A. Panduan Praktis Mempelajari Aplikasi Mikrokontroler Dan Pemrogramannya Menggunakan Arduino. Yogyakarta: Andi, 2012.

[12] Kerlinger.. Asas - Asas Penelitian Behaviour (3rd ed.). Yogyakarta: Gajah Mada University Press, 2006.

[13] Kimberly Febrina Kodrat. Evaluasi Beban Kerja Manual. Jurnal Teknik Industri, 14(2), 184-189. 2013.

[14] Latarang, Burhanuddin, and A. S. Pertumbuhan dan Hasil Bawang Merah (Allium Ascalonicum L.) Pada Berbagai Dosis Pupuk Kandang. J. Agroland, 3(13), 265-269. 2006.

[15] Nasirly, R., Aqilah, L., \& Syafei, D. Usulan HoE Dalam Perancangan Alat Pembelah Buah Pinang Dengan Metode EFD. Seminar Nasional Teknologi Informasi, Komunikasi Dan Industri (SNTIKI) 12, 470-477. 2020.

[16] Patel, N., \& Rajput, T. B. S. Effect of deficit irrigation on crop growth, yield and quality of onion in subsurface drip irrigation. International Journal of Plant Production, 7(3), 417-436. https://doi.org/10.22069/ijpp.2013.1112 2013.

[17] Wibowo, D. P., Nasifah, L., \& Berlianty, I. Perancangan Ulang Desain Kursi Penumpang Mobil Land Rover yang Ergonomis dengan Metode Ergonomic Function Deployment (EFD). Makalah Penelitian Tugas Akhir Universitas Pembangunan Nasional Veteran Yogyakarta, 1-11. 2011. 